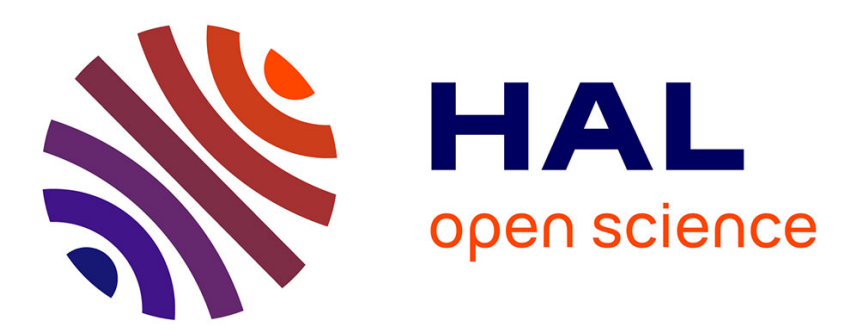

\title{
An energy-filtering device coupled to a quadrupole mass spectrometer for soft-landing molecular ions on surfaces with controlled energy
}

A. Bodin, R. Laloo, Pierre Abeilhou, L. Guiraud, Sebastien Gauthier, David Martrou

\section{To cite this version:}

A. Bodin, R. Laloo, Pierre Abeilhou, L. Guiraud, Sebastien Gauthier, et al.. An energy-filtering device coupled to a quadrupole mass spectrometer for soft-landing molecular ions on surfaces with controlled energy. Review of Scientific Instruments, 2013, 84 (9), pp.95104 - 33903. 10.1063/1.4818961 . hal01798116

\section{HAL Id: hal-01798116 https://hal.science/hal-01798116}

Submitted on 23 May 2018

HAL is a multi-disciplinary open access archive for the deposit and dissemination of scientific research documents, whether they are published or not. The documents may come from teaching and research institutions in France or abroad, or from public or private research centers.
L'archive ouverte pluridisciplinaire HAL, est destinée au dépôt et à la diffusion de documents scientifiques de niveau recherche, publiés ou non, émanant des établissements d'enseignement et de recherche français ou étrangers, des laboratoires publics ou privés. 


\section{An energy-filtering device coupled to a quadrupole mass spectrometer for soft-landing molecular ions on surfaces with controlled energy}

A. Bodin, R. Laloo, P. Abeilhou, L. Guiraud, S. Gauthier, and D. Martrou

Citation: Review of Scientific Instruments 84, 095104 (2013); doi: 10.1063/1.4818961

View online: https://doi.org/10.1063/1.4818961

View Table of Contents: http://aip.scitation.org/toc/rsi/84/9

Published by the American Institute of Physics

\section{Articles you may be interested in}

Ultrahigh vacuum deposition of organic molecules by electrospray ionization

Review of Scientific Instruments 82, 033903 (2011); 10.1063/1.3553010

Forces from periodic charging of adsorbed molecules

The Journal of Chemical Physics 146, 092327 (2017); 10.1063/1.4975607

A novel planar ion funnel design for miniature ion optics

Review of Scientific Instruments 85, 105101 (2014); 10.1063/1.4897480

Scanning tunneling microscopy imaging and manipulation of DNA oligomer adsorbed on $\mathrm{Cu}(111)$ surfaces by a pulse injection method

Journal of Vacuum Science \& Technology B: Microelectronics and Nanometer Structures Processing,

Measurement, and Phenomena 15, 602 (1997); 10.1116/1.589299

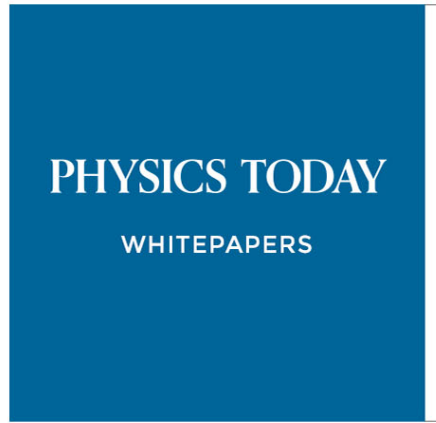

MANAGER'S GUIDE

Accelerate R\&D with

Multiphysics Simulation
READ NOW

PRESENTED BY

○ $\subset$ MMSOL 


\title{
An energy-filtering device coupled to a quadrupole mass spectrometer for soft-landing molecular ions on surfaces with controlled energy
}

\author{
A. Bodin, R. Laloo, P. Abeilhou, L. Guiraud, S. Gauthier, and D. Martrou \\ Nanosciences Group, CEMES, CNRS UPR 8011 and University Toulouse III - Paul Sabatier, 29 rue Jeanne \\ Marvig, BP94347, F-31055 Toulouse Cedex 4, France
}

(Received 5 April 2013; accepted 6 August 2013; published online 5 September 2013)

\begin{abstract}
We have developed an energy-filtering device coupled to a quadrupole mass spectrometer to deposit ionized molecules on surfaces with controlled energy in ultra high vacuum environment. Extensive numerical simulations as well as direct measurements show that the ion beam flying out of a quadrupole exhibits a high-energy tail decreasing slowly up to several hundred $\mathrm{eV}$. This energy distribution renders impossible any direct soft-landing deposition of molecular ions. To remove this high-energy tail by energy filtering, a $127^{\circ}$ electrostatic sector and a specific triplet lenses were designed and added after the last quadrupole of a triple quadrupole mass spectrometer. The results obtained with this energy-filtering device show clearly the elimination of the high-energy tail. The ion beam that impinges on the sample surface satisfies now the soft-landing criterion for molecular ions, opening new research opportunities in the numerous scientific domains involving charges adsorbed on insulating surfaces. ( 2013 AIP Publishing LLC. [http://dx.doi.org/10.1063/1.4818961]
\end{abstract}

\section{INTRODUCTION}

The deposition of organic molecules on solid surfaces is a crucial step in many technological processes, for instance, in organic electronics or in biotechnology. Indeed, the performance of the end product often depends critically on the structure of the deposit. In most cases, the principle of operation of the device requires to preserve the chemical functionality of the deposited molecules. As the sophistication of these molecules increases, the common vapor deposition method, where the compound of interest is heated under vacuum, becomes impractical because of thermal stability limitations. Alternative strategies have been imagined to prevent thermal decomposition of the molecules. It has been shown, for instance, that it can be limited by implementing pulsed heating for molecules where the activation energy for sublimation is larger than the activation energy for decomposition. ${ }^{1,2}$ But this approach is rather specific and in most cases does not totally eliminate the thermal degradation. Another method consists in injecting the molecular solution of interest directly in the vacuum chamber, in front of the sample, using a pulsed injection technique. ${ }^{3,4}$ While this technique allows depositing very fragile molecules, it suffers from the presence of the solvent, which is often difficult to eliminate from the surface. Obviously, more general alternative methods are needed.

Mass spectrometry is a key technology for chemistry, material science, and biology. Many techniques have been developed to produce ions of a huge variety of molecules, many of them thermally unstable. One of the major reasons for these achievements is that it is generally much easier to produce ions than neutrals from molecules in the bulk. In addition, these ions can be manipulated by electromagnetic fields. During the past decades, several instruments were built using these techniques to deposit ions on surfaces. They include for the majority of them different types of mass spectrometers to sort the particles and land them on a surface, with linear quadrupoles, ${ }^{5-7}$ ions traps,${ }^{8,9}$ time of flight mass spectrometers (TOF-MS), ${ }^{10}$ cyclotron resonance traps, ${ }^{11}$ electrostatic or magnetic sectors. ${ }^{12,13}$

But it is not enough to control the trajectory of the ions from the source to the surface. One has also to control the kinetic energy of the incoming ions to avoid their fragmentation by collision with the surface. It is generally considered that these "soft-landing" conditions require a kinetic energy well below $10 \mathrm{eV}$ per ion. ${ }^{14}$ This additional requirement does not apply to usual mass spectrometry, where the fragmentation of the ions in the ion detector is unimportant. As a consequence, no commercial device exists that can provide both mass selection and energy measurements of the exiting ion beam. It is then necessary to design or modify an instrument, allowing to ionize molecules gently, sort these ionized species according to their $\mathrm{m} / \mathrm{z}$ ratio, measure the energy of the selected ions, and decrease their energy just before their landing on the sample surface. Until now, two major techniques were used to decrease the energy of the ions landing on the surface. The first one is based on a retarding voltage applied directly to the target surface. ${ }^{9,10,15}$ But it is efficient only if the energy distribution of the ion beam is narrow enough. The second one is based on the damping effect of a pre-adsorbed molecular ${ }^{9}$ or atomic ${ }^{16}$ layer. But the presence of this layer is a serious limit for many applications.

We first studied by numerical simulation the physical properties of the ion beam propagating in a quadrupole. The simulation showed that the ion beam at the exit of the quadrupole presents a high-energy tail which can extend up to $1500 \mathrm{eV}$. This behavior, which is inherent to the physics of ions flying inside a quadrupole, is clearly incompatible with the soft-landing conditions that are required for organic molecules. To remove this high-energy tail, a specific energy-filtering device made of a triplet of lenses and a $127^{\circ}$ electrostatic sector was designed and optimized by simulation. Then this device was realized and inserted at the exit of the last quadrupole of a TSQ700 mass spectrometer. This 
spectrometer was coupled under ultra high vacuum (UHV) to specific UHV equipment developed for molecular electronic studies. ${ }^{17}$ The experimental results obtained with the energy filtering device demonstrate the control of the energy of $\mathrm{CF}_{3}{ }^{+}$ions landing on a surface with a precision better than $0.5 \mathrm{eV}$.

The paper is organized as follows: The kinetic energy distribution of an ion beam at the exit of a quadrupole is calculated by numerical simulations in Sec. II A while the insertion of the energy-filtering device is simulated in Sec. II B. Section III is devoted to the physical implementation of these modifications in the TSQ700 mass spectrometer. The experimental measurements that validate these modifications are reported in Sec. IV, which is followed by a short discussion in Sec. V comparing our findings with previous relevant studies. Finally, we give our conclusions and discuss future developments in Sec. VI.

\section{NUMERICAL SIMULATIONS}

\section{A. Simulation of a quadrupole with its entrance triplet of lenses}

A mass analyzer based on a quadrupole is constituted of 4 electrodes coupled two by two ${ }^{18}$ and separated by a distance $2 \mathrm{r}_{0}$. A potential $\pm \Phi_{0}=1 / 2\left(\mathrm{U}-\mathrm{V}^{*} \cos (\omega \mathrm{t})\right)$, is applied between the two electrodes of each couple, generating a quadrupolar electrical field. The trajectory $\mathrm{u}=(\mathrm{x}, \mathrm{y})$ of an ion of mass $m$ and charge $z e$ in this quadrupolar field obeys Mathieu's equation

$$
\mathrm{d}^{2} \mathrm{u} / \mathrm{d} \xi^{2}+\left(\mathrm{a}_{\mathrm{u}}+2 \mathrm{q}_{\mathrm{u}} \cos 2 \xi\right) \mathrm{u}=0
$$

with the reduced Mathieu's parameters $\mathrm{a}_{\mathrm{u}}=4 \mathrm{zeU} /\left(\mathrm{m} \mathrm{r}_{0}{ }^{2}\right.$ $\left.\omega^{2}\right), \mathrm{q}_{\mathrm{u}}=2 \mathrm{zeV} /\left(\mathrm{m} \mathrm{r}_{0}^{2} \omega^{2}\right), \xi=\omega \mathrm{t} / 2$. The resolution of this equation gives the stability domain for the ions, expressed in terms of $a_{u}$ and $q_{u}$, which are then used experimentally to select the value of U and V. Although the Mathieu's equation gives the trajectory of the ions in the quadrupolar electrical field, it cannot be used anymore after the exit of the quadrupole. To our knowledge no analytical solutions exist to express the physical parameters of the ions getting out of a quadrupole. Some numerical and theoretical studies have been performed to understand the effects of the fringing fields at the entrance of quadrupoles on the acceptance, sensitivity, and resolving power. ${ }^{19}$ But these studies did not give information on the kinetic energy of the ions after the exit of the quadrupole. Consequently, we had to rely on numerical simulations to evaluate it.

SIMION ${ }^{\circledR} 8.4 .0$ is a software dedicated to simulating ions trajectories in electrostatic and electromagnetic environments. It solves simultaneously the Laplace and the Newton equations by a finite-difference method. In our case, the calculations were performed using a quasi-static approximation, where the magnetic fields generated by the time varying potentials are neglected, due to the rather low frequencies involved (1 MHz at most). The parameters that determine the quality of the simulation are the size of the unit grid and the time between successive calculations of the quasi-static potentials. The size of the unit grid is constrained by the memory size of the computer and the volume of the model. We have determined that a grid unit of $0.25 \mathrm{~mm}$ gives an error of less than $5 \%$ on the trajectory compared to a unit grid of $0.125 \mathrm{~mm}$. The time of $0.01 \mu$ s between each step is linked to the RF frequencies of $1 \mathrm{MHz}$ and $900 \mathrm{kHz}$ applied to the Q1 and Q3 quadrupoles of the experimental TSQ700 mass spectrometer used to implement the energy-filtering device.

The other parameters for the simulation belong to the initial ion beam: the mean kinetic energy (KEi) and its dispersion $(\Delta \mathrm{KEi})$ and the half angle dispersion $(\Delta \alpha)$. The mean energy is related to the flying time inside the quadrupole. The TSQ700 documentation gives a value for the translational kinetic energy (TKE) of $5 \pm 2 \mathrm{eV}$ that corresponds to an optimized residence time inside the quadrupole. Thus, we have performed a first study with the model presented in Fig. 1 to determine the value of $\mathrm{KEi}$ as a function of the ion mass $\mathrm{m}$ with a positive charge $z e=1$, in order to fix TKE $=1 / 2 \mathrm{mV}_{\mathrm{z}}{ }^{2}$ at $5 \mathrm{eV}$. The model of the quadrupole and its three entrance lenses was determined from the real assembly of TSQ700 pieces. The rods have a parabolic shape that approximates the real hyperbolic shape with a precision better than $0.1 \mathrm{~mm}$. The distance between two opposite rods is $2 \mathrm{r}_{0}=9 \mathrm{~mm}$. The length of the rods is $160 \mathrm{~mm}$. The distance between each lens is $3.5 \mathrm{~mm}$ and their thickness is $0.5 \mathrm{~mm}$. The grid unit size for the model is $0.25 \mathrm{~mm}$.

The control parameters for the quadrupole model are:

1. The Mathieu's parameters, that are determined by the position of the tip of the stability diagram at $a_{u}$ $=0.23699$ and $\mathrm{q}_{\mathrm{u}}=0.706$ and by the percent tune parameter, fixed in our study at 0.99 , giving $\mathrm{a}_{\mathrm{u}}=0.2346$.

2. The value of the $U$ and $V$ potentials applied to the rods $\left( \pm \Phi_{0}=1 / 2\left(U-V^{*} \cos (\omega t)\right)\right.$, deduced from the value of the Mathieu's parameters. In order to optimize the resolution and the selectivity of the simulated quadrupole, the value of $r_{0}$ which appears in the expression of these parameters was used as an adjustable parameter. This study shows that the best value for $r_{0}$ is $4.45 \mathrm{~mm}$ instead of the real, physical value of $4.5 \mathrm{~mm} .{ }^{20}$

3. The value of quad axis DC voltage fixed at $-10 \mathrm{~V}$, the experimental value used in the TSQ700, which is added to the rod potential $\pm \Phi_{0}$.

4. The RF frequency of the quad equal to $1 \mathrm{MHz}$.

5. The voltages applied to the lenses $\mathrm{L} 31=\mathrm{L} 33=-30 \mathrm{~V}$ and $\mathrm{L} 32=-180 \mathrm{~V}$ corresponding to the experimental values optimized by the auto tune routine of the Finnigan software.

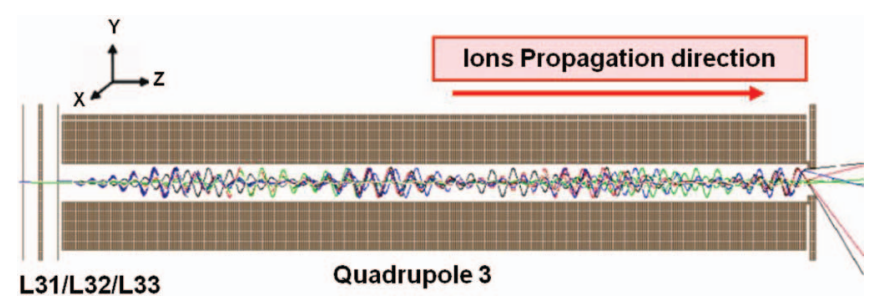

FIG. 1. SIMION model of Q3 and its three entrance lenses. Ten ions of mass $1000 \mathrm{u}$ and charge $\mathrm{z}=1$ are flying through the quadrupole. 

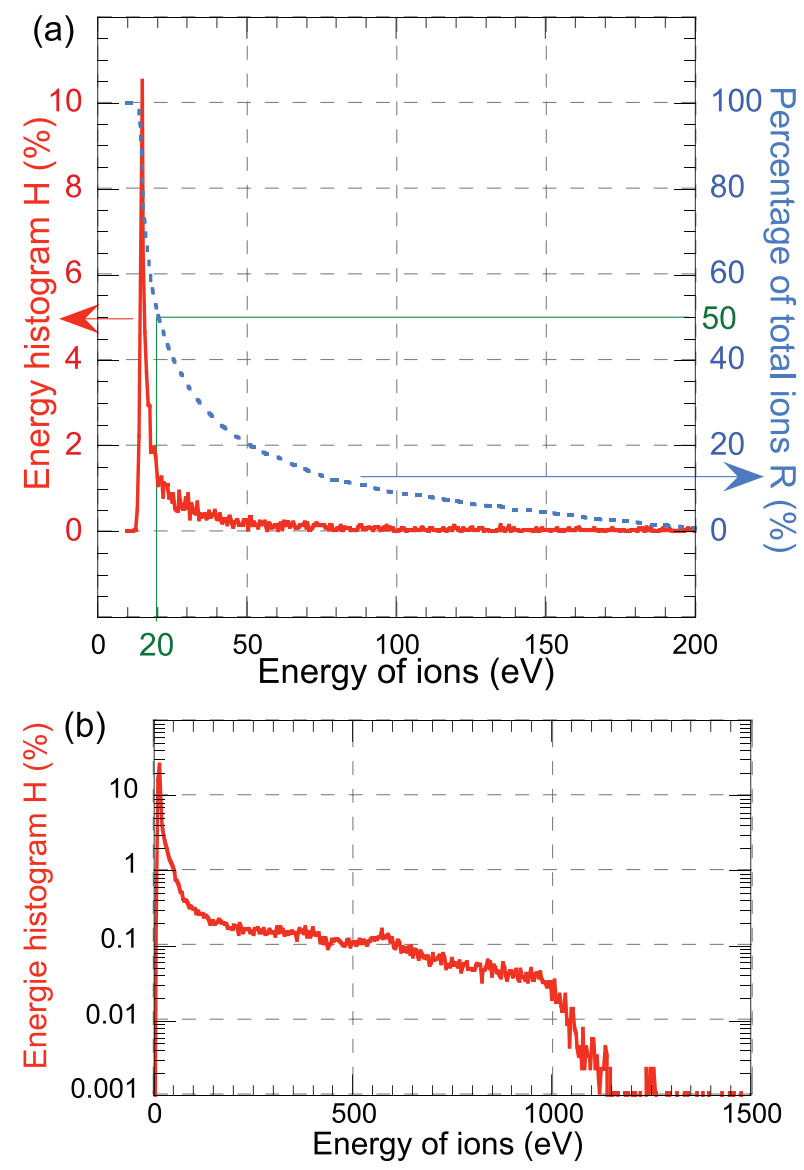

FIG. 2. (a) Simulated energy histogram $\mathrm{H}\left(\mathrm{E}_{\text {ions }}\right)$ (solid red curve) and the percentage of ions having an energy higher than $E_{\text {ions }} R\left(E_{\text {ions }}\right)$ (dotted blue curve). (b) Energy histogram $\mathrm{H}\left(\mathrm{E}_{\text {ions }}\right)$ presented with a semi-logarithmic scale.

As shown in Fig. 1, the ions fly along the quadrupole with the typical double period oscillating trajectory. At the exit of the quadrupole, the ions have a linear trajectory with no specific angle direction. To check that the behavior of the ion beam at the exit of the quadrupole is independent of the initial parameters, we performed numerous simulations with various $\Delta \mathrm{KEi}$ and $\Delta \alpha$. We did not find any relation between these two parameters and the energy or angle distributions of the exit ion beam. Only the number of transmitted ions was affected, due to the effective collimation of the three stack lenses. After this study, we chose $\Delta \mathrm{KEi}=0$ and $\Delta \alpha=2^{\circ}$.

Fig. 2 shows the simulated energy distribution of the exit ion beam. The energy histogram $\mathrm{H}\left(\mathrm{E}_{\text {ions }}\right)$ (red curve) is obtained from the analysis of 100000 ion flights. The blue curve $R\left(E_{i o n s}\right)$ shows the percentage of ions with an energy higher than $E_{\text {ions }}$, obtained by integration of $\mathrm{H}$ from $\mathrm{E}_{\text {ions }}$ to the maximal energy. In Fig. 2(a), the histogram $\mathrm{H}\left(\mathrm{E}_{\text {ions }}\right)$ shows a peak with a maximum near $15 \mathrm{eV}$, but this peak is not symmetric. A high-energy tail is observed up to $1500 \mathrm{eV}$. It decreases very slowly, as better seen in the semi-logarithmic representation of Fig. 2(b). Indeed, the green lines in Fig. 2(a) indicate that $50 \%$ of the ions have an energy higher than $20 \mathrm{eV}$. These observations are somewhat surprising since the presence of these high energy ions in the output beam of a quadrupole, which makes soft-landing conditions more difficult to reach, was not reported before.

We also observed that there are no correlations between the energy and the elevation angle of the ions at the exit of the quadrupole. In addition, the kinetic energy along the propagation direction $\mathrm{z}$ or TKE also presents a high energy tail up to $1200 \mathrm{eV} .^{20}$ These observations indicate that it would be impossible to eliminate all these high-energy ions by a simple collimation. Indeed, a high-energy tail is still present up to $500 \mathrm{eV}$ after the fly of the ion beam through a triplet of lenses. $^{20}$

The observation of the high-energy tail in TKE gives the clue for its physical origin: In an ideal quadrupole, the electric field has no component along $\mathrm{z}$, meaning that the $\mathrm{z}$ component of the velocity of the ions should be conserved during the crossing of the quadrupole. The presence of the high-energy tail in TKE means that the ions have been accelerated along z. This can only happen near the entrance or the output of the quadrupole, where the electric field is non-zero along $\mathrm{z}$ due to the large potential difference between the lenses and the quadrupole electrodes. The value of this electric field depends on the phase of the RF voltage when a particular ion is launched in the simulation. It is this phase, which is not controlled in SIMION, that masks the correlations that could be observed otherwise between the input and output parameters of the ion beam.

A confirmation of this explanation in terms of fringing fields is the observation that the maximum value of the energy is directly linked to the rod potential. This potential is proportional to the ion mass $\mathrm{m}$ for fixed Mathieu's parameters. Simulation results obtained for ions of mass 219 and $69 \mathrm{u}$ show that the high-energy tails are still observed, ${ }^{20}$ with maximum values $(330 \mathrm{eV}$ and $105 \mathrm{eV})$ that are proportional to the ion mass, with the simple empirical relation: $\mathrm{E}_{\max }$ $=1.5 \times \mathrm{m}_{\text {ions }} / \mathrm{z}$.

The experimental observation of this high-energy tail will be reported in Sec. III.

\section{B. Simulation of the electrostatic sector}

The presence of the high energy tail imposes an energyfiltering stage before slowing down the ions to achieve softlanding conditions on the substrate. Because of the limited space available in the manifold of our experimental setup, we chose to use an electrostatic sector. The theory of the ideal $127^{\circ}$ electrostatic sector is well known: ${ }^{21}$ the value of the low pass cutoff energy $E_{f}$ depends only on the potential $V_{s}$ applied to each sector according to the relation $E_{f}=V_{s} / k$ with $k=2\left(R_{1}-R_{2}\right) /\left(q\left(R_{1}+R_{2}\right)\right)$ and $R_{1}, R_{2}$ the radii of the two sectors as shown in Fig. 3. $R_{1}$ and $R_{2}$ were fixed to 35 and $25 \mathrm{~mm}$, respectively, for the device to fit in the available space. These values give $k=0.333$.

The sides of the electrostatic sector were equipped with polarizable screens in order to confine the ions to the center of the electrostatic sector and increase its transmittance. The width of the sector was adjusted to $40 \mathrm{~mm}$ to minimize the distortion of the filtering potential induced by the sectors. ${ }^{20}$ 

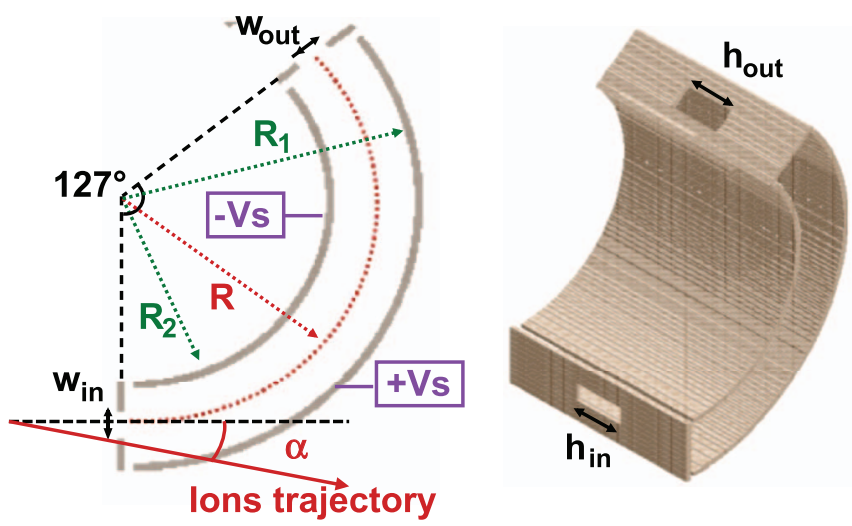

FIG. 3. Schematic view of the electrostatic sector with its geometrical parameters.

The energy resolution is related to $R_{1}$ and $R_{2}$, to the geometrical parameters $h_{\text {in }}, h_{\text {out }}, w_{\text {in }}, w_{\text {out }}$ of the sector entrance and exit windows and to the elevation angle $\alpha$ of the ions by ${ }^{21}$

$$
\begin{aligned}
\frac{\Delta E}{E}= & \frac{4}{3} \alpha^{2}+\frac{1}{2}\left(\frac{h_{\text {in }}+h_{\text {out }}}{\pi \mathrm{R}}\right)^{2} \\
& +\frac{w_{\text {in }}+w_{\text {out }}}{R}, \text { with } R=\left(R_{1}+R_{2}\right) / 2 .
\end{aligned}
$$

For $h_{\text {in }}=h_{\text {out }}=10 \mathrm{~mm}, w_{\text {in }}=w_{\text {out }}=3 \mathrm{~mm}, R_{1}=35 \mathrm{~mm}$, and $R_{2}=25 \mathrm{~mm}$, the sum of last two terms is equal to 0.2 . The first term shows a parabolic dependence on the elevation angle $\alpha$ for $\alpha=10^{\circ}$ (resp. $45^{\circ}$ ), it is equal to 0.04 (resp. 0.82).

Fig. 4(a) presents the simulated trajectories of 10000 ions at the exit end of the quadrupole for the original configuration of the mass spectrometer. The corresponding angular distribution (blue curve, Fig. 4(c)) extends up to $60^{\circ}$. More precisely, $72 \%$ of the ions have an elevation angle $\alpha$ higher than $10^{\circ}$. This means that the filter in energy will have a high dispersion in energy. So it is necessary to decrease as much as possible the elevation angle of the ions.

To reduce the angular dispersion of the ion beam before the filter, we tried numerous stack of 3 lenses with different thicknesses, spacers and hole diameters. The stack of lenses L41-L42-L43, optimized for ions with $\mathrm{E}_{\text {ions }}<100 \mathrm{eV}$, is made of lenses $3 \mathrm{~mm}$ thick, with $5 \mathrm{~mm}$ holes, separated by $1 \mathrm{~mm}$ spacers. Fig. 4(b) presents the simulated trajectories of 10000 ions after the polarized lenses $(\mathrm{L} 41=\mathrm{L} 43=0 \mathrm{~V}, \mathrm{~L} 42$ $=-60 \mathrm{~V}$ ). The corresponding angular distribution (red curve, Fig. 4(c)) extends up to $20^{\circ}$ and only $17 \%$ of the ions have an elevation angle higher than $10^{\circ}$, compared to $72 \%$ in the original configuration. The relative energy dispersion $\Delta \mathrm{E} / \mathrm{E}$ calculated from Eq. (2) for the original TSQ700 configuration (blue curve) and for the modified exit with the triplet lenses (red curve) are presented in Fig. 4(d). For the original configuration, $\Delta \mathrm{E} / \mathrm{E}$ decreases slowly to 1.5 : for only $36 \%$ of ions $\Delta \mathrm{E} / \mathrm{E}$ is lower than 0.23 . The modified configuration shows a faster decrease: $90 \%$ of ions have a $\Delta \mathrm{E} / \mathrm{E}<0.23$.

Adding the designed stack of lenses and the electrostatic sector to the model after the quadrupole allows verifying the behavior of the whole system. Fig. 5 shows the histograms $\mathrm{H}\left(\mathrm{E}_{\text {ions }}\right)$ for 5000 ions flies, after the stack of lenses (L41-L42L43) and after the electrostatic sector. The voltage parameters
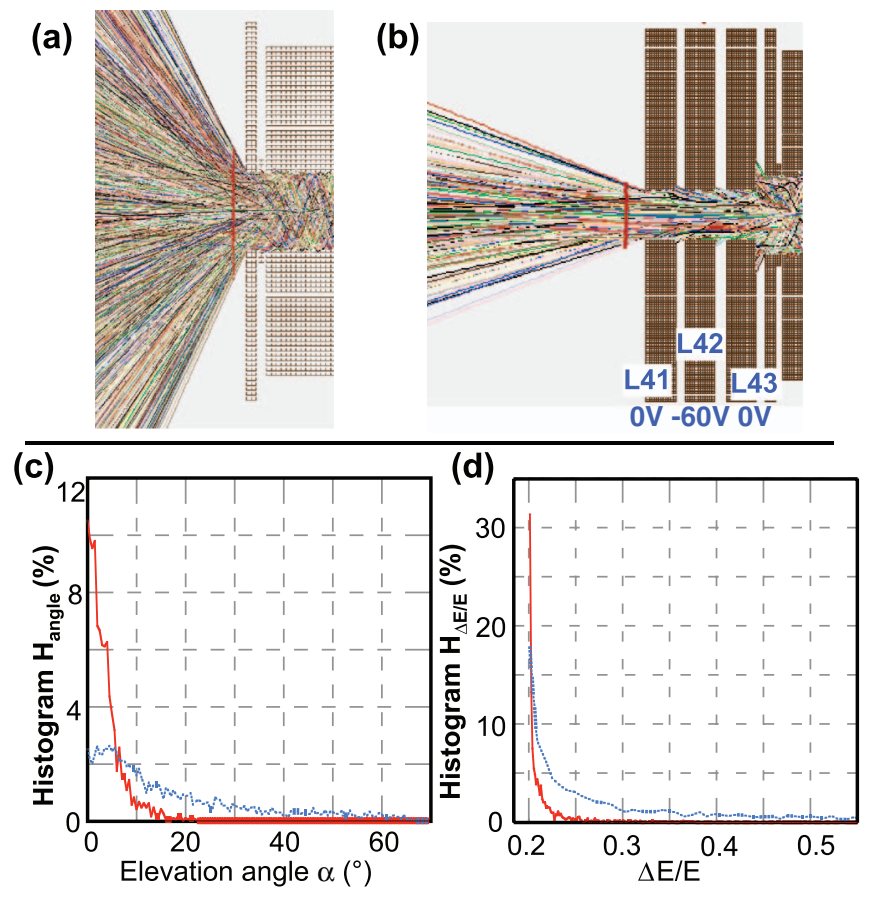

FIG. 4. Simulated trajectories of 10000 ions of mass 1000 flying in SIMION at the exit of the quadrupole in (a) its original configuration, and (b) after the electrostatic triplet of lenses. (c) Elevation histogram $\mathrm{H}_{\text {angle }}$ comparison with (solid red curve) and without (dashed blue curve) the electrostatic triplet of lenses. (d) $\Delta \mathrm{E} / \mathrm{E}$ histogram $\mathrm{H}_{\Delta \mathrm{E} / \mathrm{E}}$ for the original configuration (dashed blue curve) and with the electrostatic triplet of lenses (solid red curve).

$\mathrm{V}_{\mathrm{s}}=4.773 \mathrm{~V}$ and $\mathrm{V}_{\text {screen }}=+13 \mathrm{~V}$ were adjusted in the simulation to get the higher yield for $\mathrm{E}_{\mathrm{ions}}=14.6 \mathrm{eV}$. For this ion energy, the theoretical value given by the relation $V_{s}=E_{\text {ions }}$ $\times k$ with $k=2\left(R_{1}-R_{2}\right) /\left(q\left(R_{1}+R_{2}\right)\right)$ is equal to $4.86 \mathrm{~V}$, in good agreement with the simulation.

The high-energy tail after L41-L42-L43 is still clearly visible in the semi-logarithmic graph of Fig. 5(b). The maximum energy of the ions is now around $400 \mathrm{eV}$, instead of $1500 \mathrm{eV}$ at the output of the quadrupole [Fig. 2(b)]. But this decrease is not sufficient since still $25 \%$ of the ions have an energy higher than $20 \mathrm{eV}$, which is more than $5 \mathrm{eV}$ higher than the peak energy. Consequently, applying a retarding voltage of, e.g., $13 \mathrm{~V}$ on the plate with such an ion beam would be clearly inefficient to satisfy the soft landing criterion.

The green curves in Figs. 5(b) and 5(c) clearly show that the electrostatic sector removes the high energy tail; the peak in the energy distribution is centered at $13.8 \mathrm{eV}$ with a width of approximately $3 \mathrm{eV}$, giving a value of $\Delta \mathrm{E} / \mathrm{E}$ equal to 0.217 close to the theoretical value calculated before. The shift in energy from $14.6 \mathrm{eV}$ to $13.8 \mathrm{eV}$ is induced by the fringing fields at the exit of the electrostatic sector. With such an energy distribution, soft-landing conditions are easily achieved by applying a voltage to the sample plate: with $13 \mathrm{~V}$, all the ions have an energy below $4 \mathrm{eV}$ that guarantees their integrity after landing (red curve, Fig. 5(c)). Note that only $25 \%$ of the incoming ions are transmitted by the sector.

The simulation and the optimization of the stack of lenses and the electrostatic sector were made with ions of mass 1000 $\mathrm{u}$ and charge $z e=+1$. However, we checked that the design of the different elements also works satisfactorily for ions with 

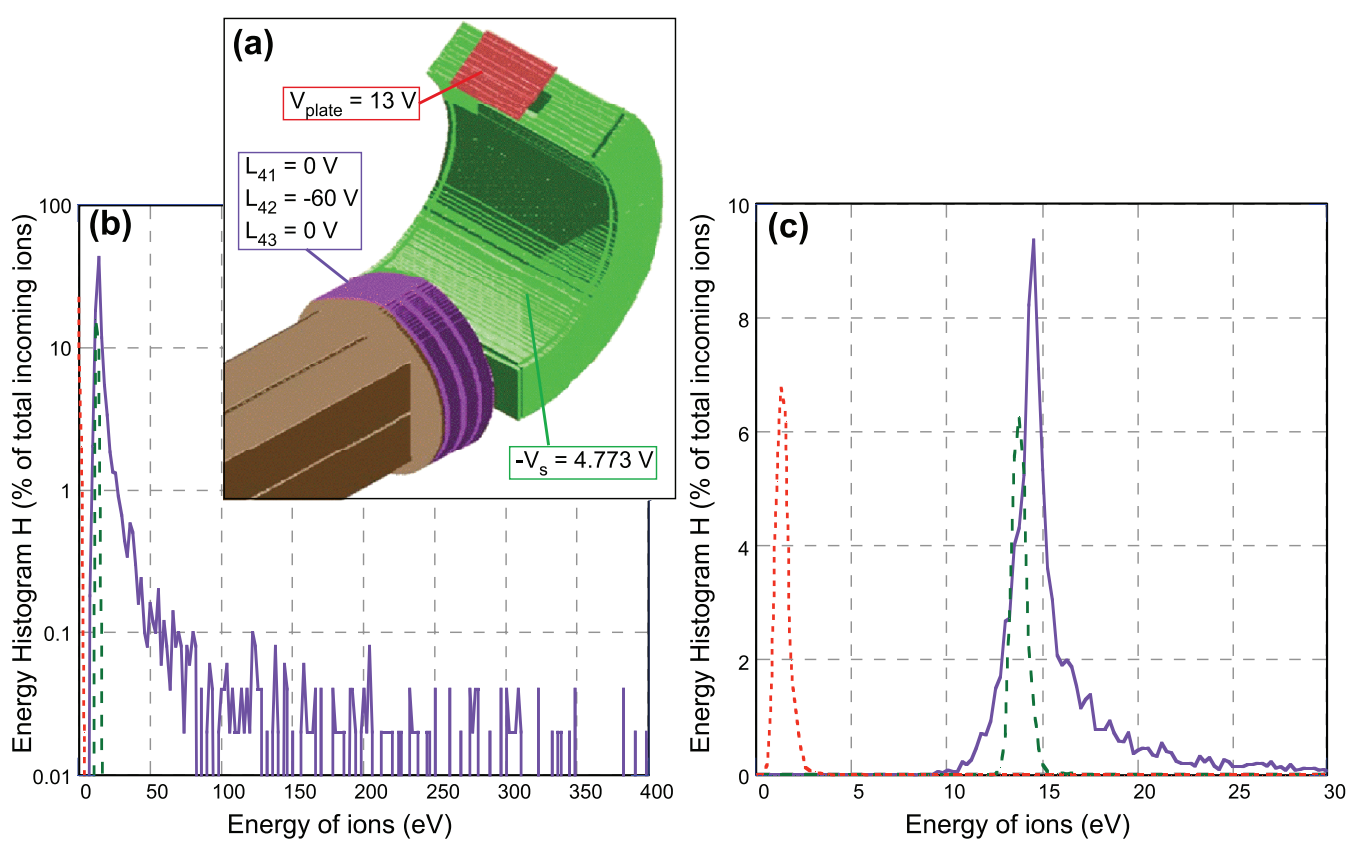

FIG. 5. (a) 3D view of the different parts of the energy filtering device, (b) simulated energy histogram $\mathrm{H}\left(\mathrm{E}_{\text {ions }}\right)$ of the ion beam after the L4 stack of lenses (solid purple curve), after the electrostatic sector polarized at $4.773 \mathrm{~V}$ (dashed green curve) and on the sample plate (dotted red curve) polarized at $13 \mathrm{~V}$ (semi-logarithmic scale), and (c) zoom of the energy histogram $\mathrm{H}\left(\mathrm{E}_{\mathrm{ions}}\right)$ (linear scale).

masses ranging from 50 to $2000 \mathrm{u}$. As presented in Sec. IV, the experimental results obtained for ions of mass 69 and $219 \mathrm{u}$ are in very good agreement with the numerical simulation predictions.

The simulation of ions fly inside a quadrupole allowed us to evidence the high-energy tail. This phenomenon should be common to all types of quadrupoles. It is related to the high $\mathrm{RF}$ voltage necessary to realize the $\mathrm{m} / \mathrm{z}$ filtering. To filter this high-energy tail, we have designed and optimized an energyfiltering device composed of a triplet of lenses and a $127^{\circ}$ electrostatic sector. The implementation of this device in a commercial mass spectrometer is described in Sec. III.

\section{DESIGN AND ASSEMBLY OF THE ENERGY-FILTERING DEVICE COUPLED TO THE QUADRUPOLE MASS SPECTROMETER}

The energy-filtering device was implemented in a triple quadrupole mass spectrometer TSQ700 from Finnigan Company. The advantages of this equipment are numerous: (1) all the analyzer components are easily accessible through the top of the vacuum chamber, (2) there is enough space after the last quadrupole to implement the energy-filtering device, (3) the control system is based on easily modifiable analogic electronics, and (4) the control system is interfaced by a user friendly software that gives access to all the electrostatic parameters of the quadrupoles and the lenses. In order to study ionized molecules deposited on insulating substrates such as $\mathrm{KBr}(001)$ or $\mathrm{AlN}(0001)$, the mass spectrometer TSQ700 was integrated in a specific homemade UHV equipment called UHV factory. ${ }^{17}$ This equipment allows transferring samples under UHV between the spectrometer, a molecular beam epitaxy chamber dedicated to the growth of $\operatorname{AlN}(0001)$ substrates, a surface preparation chamber, a UHV atomic force microscope (AFM) (Omicron nanotechnology) working at room temperature, and a second UHV AFM modified to perform nanostencil experiments and electrical measurements on a molecular junction in a planar configuration. ${ }^{17}$

The mass spectrometer TSQ700 accepts several inlet sources such as Electron Ionization (EI) or ElectroSpray Ionization (ESI) sources. Its main body is constituted of two mass analyzers based on quadrupole rod assemblies separated by a curved quadrupole for X-ray and neutral molecules filtering. The ionized ions enter into the source chamber heated at $150^{\circ} \mathrm{C}$ and pumped with a $300 \mathrm{l} / \mathrm{s}$ turbomolecular pump allowing to reach a vacuum of $10^{-3}$ Torr. The ion beam is collimated by two electrostatic lenses with $5 \mathrm{~mm}$ holes, called L11 and L12, and enters into the first quadrupole rod assembly Q1 working at $1 \mathrm{MHz}$ RF frequency. The three quadrupoles are placed in a second $\mathrm{HV}$ chamber heated at $70^{\circ} \mathrm{C}$ and pumped with a $300 \mathrm{l} / \mathrm{s}$ turbomolecular pump to reach a vacuum below $10^{-8}$ Torr. After the first quadrupole Q1, the ion beam is focused again with the L21, L22, L23 stack of lenses and then enters into the curved quadrupole Q2 for X-rays and neutrals filtering. This curved quadrupole Q2 can also be used for collision experiments with a neutral gas like Ar or $\mathrm{He}$, but we did not work with this option during our development. After Q2, the ion beam is focused again with the L31, L32, L33 lenses to enter into the last quadrupole Q3 working at $0.9 \mathrm{MHz}$ RF frequency. The Q2 RF frequency is automatically linked by means of a phase locked loop to the frequency of the quadrupole (Q1 or Q3) used for mass filtering. The detection system is based on a high voltage dynode $(20 \mathrm{kV})$ coupled to a channeltron amplifier. This detector generates high electric fields near the exit of the last quadrupole. Our first simulations and experiments showed that these fields strongly perturb the ion beam. We have thus replaced this detector assembly by a microchannel plate (MCP) F4655 from Hamamatsu 


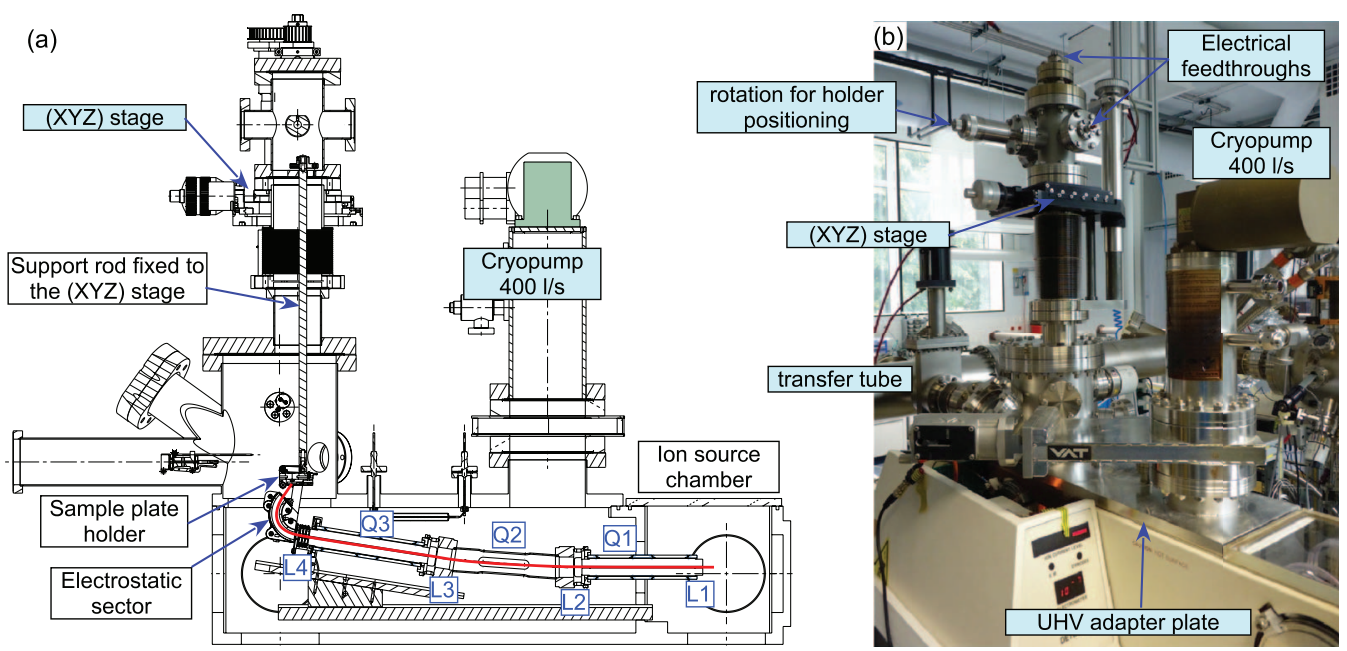

FIG. 6. (a) Cross section of the DAO assembly: the red lines indicate the fly of the ion beam through the different parts. (b) View of the modified TSQ700 with the UHV adapter plate and the UHV tools necessary for pumping and sample transfer.

Company, with a gain of $10^{6}, 10$ times higher than the gain of the original dynode assembly. This modification does not add extra electronic noise to the normal MS acquisition spectra and drastically reduces the electric field at the exit of the last quadrupole. The RF and DC electronic control of the three quadrupoles can be switched between two mass ranges of ionized molecules: low mass range (LMR) up to $2000 \mathrm{u}$ and high mass range (HMR) between 2000 and $4000 \mathrm{u}$. In this paper, we present results obtained for LMR range, fixed by the mass of $671 \mathrm{u}$ of the calibration compound $\mathrm{FC} 43\left(\left(\mathrm{CF}_{3}\left(\mathrm{CF}_{2}\right)_{3}\right)_{3} \mathrm{~N}\right)$ used in our studies.

Three kinds of modification were necessary to install our energy-filtering device in the TSQ700. All these improvements were designed with CATIA software taking into account the usual restrictions imposed by the UHV environment on the design and the materials. The first two modifications belong to the vacuum pumping and to the coupling to the other UHV chambers. A thick glass plate closing the HV chamber of the spectrometer in its original configuration was replaced by a $20 \mathrm{~mm}$ thick stainless steel UHV adapter plate with one DN150CF chamber, one DN100CF, and two DN19CF UHV flanges to mount the additional UHV tools (Fig. 6). The pumping speed was increased by means of a CT100 cryopump mounted on the DN100CF flange. The DN150CF chamber allows (1) the connection to the UHV transfer tube that connects the spectrometer to the preparation and AFM chambers of the UHV factory, ${ }^{17}$ (2) the visualization inside the TSQ700 for sample transfer and manipulator positioning, (3) the measurement of the vacuum level via a Pirani Penning gauge, (4) the assembly of the (XYZ) manipulator where the electrostatic tool and the electrical feedthroughs are mounted.

The transfer of the Omicron sample plate is performed with a standard transfer head in horizontal position. But the electrostatic sector presenting an angle of $127^{\circ}$, the sample plate should be rotated to be positioned perpendicularly to its exit axis. The design of the electrostatic sector and the sample plate holder integrate some mechanical and electrical constraints: all the different parts of the electrostatic sector are electrically insulated. To allow a better design, we chose to use metal laser sintering, which allows the fabrication of pieces that would not be realizable by more conventional techniques. All the pieces are made of stainless steel 304L, and they are mirror polished on the path of the ion beam. Fig. 7(a) shows a 3D drawing of the new device, while Figs. 7(b) and 7(c) show its real assembly.
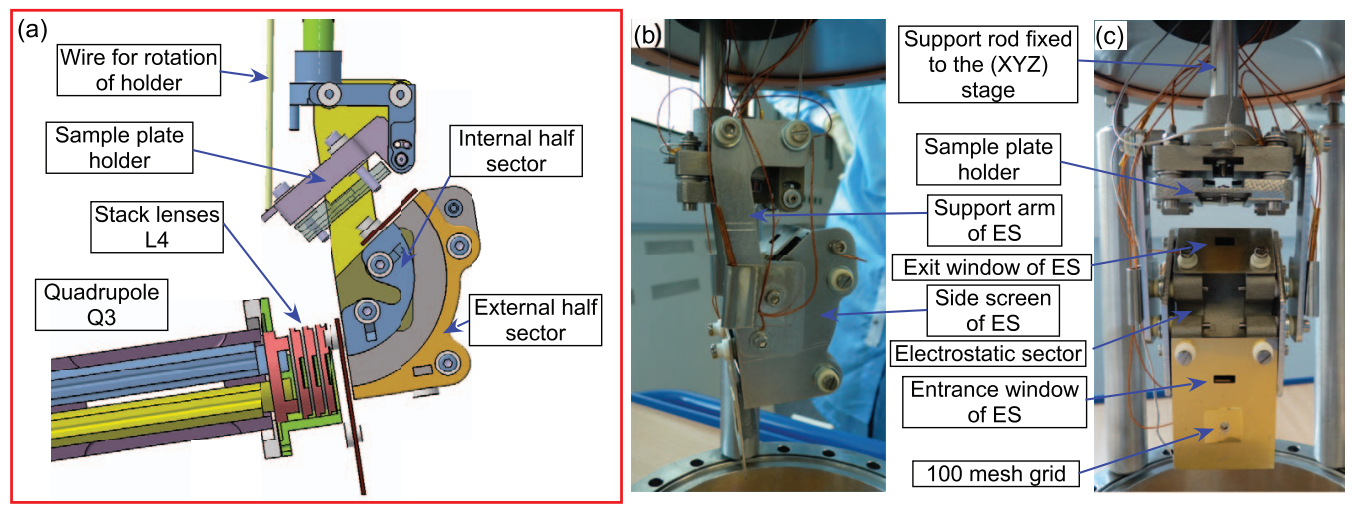

FIG. 7. (a) 3D drawing of the modified exit of the TSQ700, with the collimating stack lenses L4, the electrostatic sector, and the sample plate holder; (b) and (c) pictures of the real assembly. 
To measure the energy of the ions, a 100 mesh copper grid $(\varnothing=3.05 \mathrm{~mm}, 250 \mu \mathrm{m}$ pitch, $200 \mu \mathrm{m}$ hole, and thickness of $35 \mu \mathrm{m}$ ) was added below the entrance window of the electrostatic sector. Only the ions with $E_{\text {ions }}>\mathrm{e} V_{\text {grid }}$ will be able to pass through the grid polarized at $\mathrm{V}_{\text {grid. }}$. The device behaves as a nearly ideal high pass filter with an energy cutoff $\mathrm{eV}_{\text {grid. }}$. In these conditions $-\mathrm{dI}_{\text {ions }} / \mathrm{dV}_{\text {grid }}$, where $\mathrm{I}_{\text {ions }}$ is the current passing through the grid and measured on the MCP gives the energy distribution in the ion beam. As detailed in Ref. 22, this kind of grid allows an energy precision of $0.1 \mathrm{eV}$ for $\mathrm{E}_{\text {ions }}<20 \mathrm{eV}$.

Note that $\mathrm{I}_{\text {ions }}\left(\mathrm{V}_{\text {grid }}\right)$ and $-\mathrm{dI}_{\text {ions }} / \mathrm{dV}_{\text {grid }}\left(\mathrm{V}_{\text {grid }}\right)$ measured in this way will be directly comparable to the simulated quantities $\mathrm{H}\left(\mathrm{E}_{\text {ions }}\right)$ and $\mathrm{R}\left(\mathrm{E}_{\text {ions }}\right)$ shown in Fig. 2.

To electrically supply the filtering device, 7 independent power supplies are needed:

1. $\quad \mathrm{L} 41=\mathrm{L} 43$ lenses of our specific triplet of lenses

2. L43 lens of our specific triplet of lenses

3. $\mathrm{V}_{\text {grid }}$ trigged by the TSQ acquisition

4. $+\mathrm{V}_{\mathrm{s}}$ applied on the external half sector trigged to the TSQ acquisition

5. $-\mathrm{V}_{\mathrm{s}}$ applied on the internal half sector trigged to the TSQ acquisition

6. $\mathrm{V}_{\text {screen }}$ applied on the two sector screens

7. $\mathrm{V}_{\text {sample }}$

As the two stack lenses L2 and L3 have voltage values with differences lower than $10 \mathrm{~V}$, we have coupled electrically the lenses two by two, and used the free power supplies of L3 stack lenses for our additional L4 stack lenses. Thus, the adjustment of L4 voltages can be easily obtained with the auto tune routine of the TSQ700 software or by hand. The other voltages were obtained from low noise power supplies with $10 \mathrm{mV}$ precision, with their voltage reference connected to the ground of the TSQ700 electronics. The measure of the current on the sample plate is performed by means of a Keithley 480 picoammeter that shows a noise of $20 \mathrm{fA}$ when connected to the sample plate.

\section{EXPERIMENTAL RESULTS}

Once the mechanical and electrical modifications were implemented in the TSQ700, the first experiment consisted in verifying the overall capacities of the spectrometer in MS mode with Q1 or Q3, without the manipulator in the ion beam path. All the experiments were performed with the calibration compound $\left.\mathrm{FC} 43\left(\mathrm{CF}_{3}\left(\mathrm{CF}_{2}\right)_{3}\right)_{3} \mathrm{~N}\right)$ with a mass of $671 \mathrm{u}$, and a low room temperature vapor pressure of 1 Torr. Its ionization is easily obtained with the electron ionization source of the TSQ700. As shown in the MS spectrum of Fig. 8 obtained with $\mathrm{Q} 3$, the majority peaks correspond to the fragments $\mathrm{CF}_{3}{ }^{+}(\mathrm{m} / \mathrm{z}=69)$ and $\mathrm{C}_{3} \mathrm{~F}_{9}{ }^{+}(\mathrm{m} / \mathrm{z}=219)$. This spectrum demonstrates that the modifications did not alter notably the performances of the spectrometer. In addition, the replacement of the dynode + channeltron detection by the microchannel plate increased its sensitivity by a factor of 10 .

For the energy measurement of the ion beam at the exit of Q3, we used the 69 and 219 u peaks. The first step was to optimize the voltage values on the new L4 stack lenses. This was achieved by placing the grounded dedicated copper grid

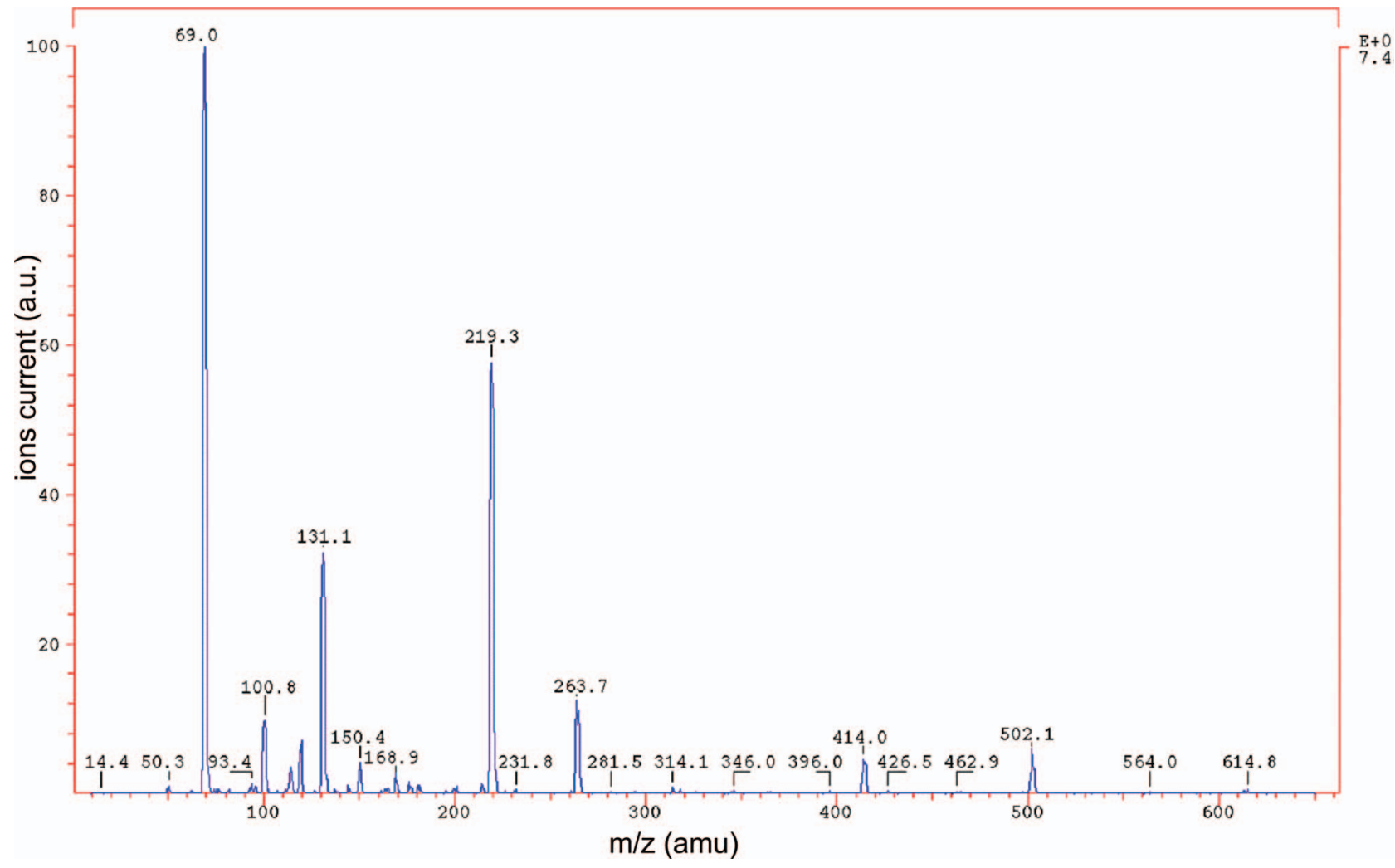

FIG. 8. Mass spectrum of the FC43 compound obtained with the modified TSQ700. 
at $10 \mathrm{~mm}$ from the exit of L4. The ion intensity was then measured as a function of the voltage on L41 = L43 and on L42 to determine for which values the ion beam becomes parallel.

Once these adjustments were performed, the grid was approached at $1 \mathrm{~mm}$ from the exit of L4 and the ion current reaching the MCP was measured while the grid voltage was increased. The ion current was determined by integration over a mass window of $0.6 \mathrm{u}$ around $\mathrm{m} / \mathrm{z}=219$. The acquisition time for this scan was $5 \mathrm{~s}$ and this acquisition was repeated with a grid voltage increment of $1 \mathrm{~V}$ from 0 to $200 \mathrm{~V}$, which is the maximum admissible voltage for the Kapton electrical wires that are used in the spectrometer. Fig. 9 shows the resulting $\mathrm{I}_{\text {ions }}\left(\mathrm{V}_{\text {grid }}\right)$ and $-\mathrm{dI}_{\text {ions }} / \mathrm{dV}_{\text {grid }}$ measured for $\mathrm{m} / \mathrm{z}=219$ ions. As expected (see the discussion in Sec. III), the shape of the curves are quite similar to the simulated curves $\mathrm{R}\left(\mathrm{E}_{\text {ions }}\right)$ and $\mathrm{H}\left(\mathrm{E}_{\text {ions }}\right)$ presented in Figs. 2 and 5 obtained for ions of $1000 \mathrm{u}$. They also compare quite well with the simulated curves obtained with ions of 219 u. ${ }^{20}$ One can observe the
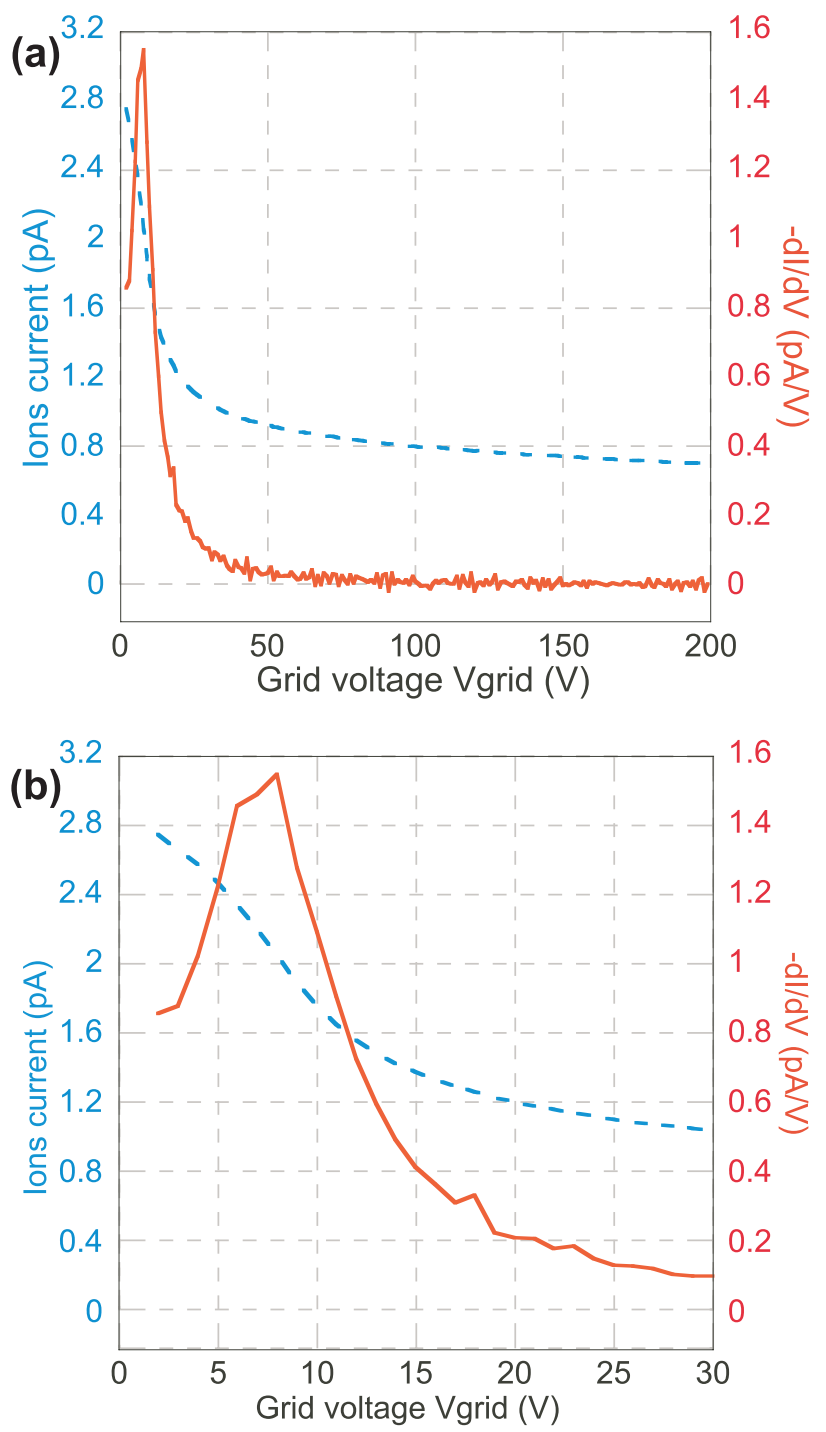

FIG. 9. Measurement of the ion energy distribution at the exit of Q3 by high pass energy filtering: (a) Ion current $\mathrm{I}_{\text {ions }}$ (dashed blue curve) and negative derivative $-\mathrm{dI}_{\text {ions }} / \mathrm{dV}_{\text {grid }}$ (solid red curve) as a function of the grid voltage $\mathrm{V}_{\text {grid }}$, obtained for ions $\mathrm{C}_{3} \mathrm{~F}_{9}{ }^{+}$of $\mathrm{m} / \mathrm{z}=219$ at the $\mathrm{Q} 3$ output. (b) Zoom of (a).
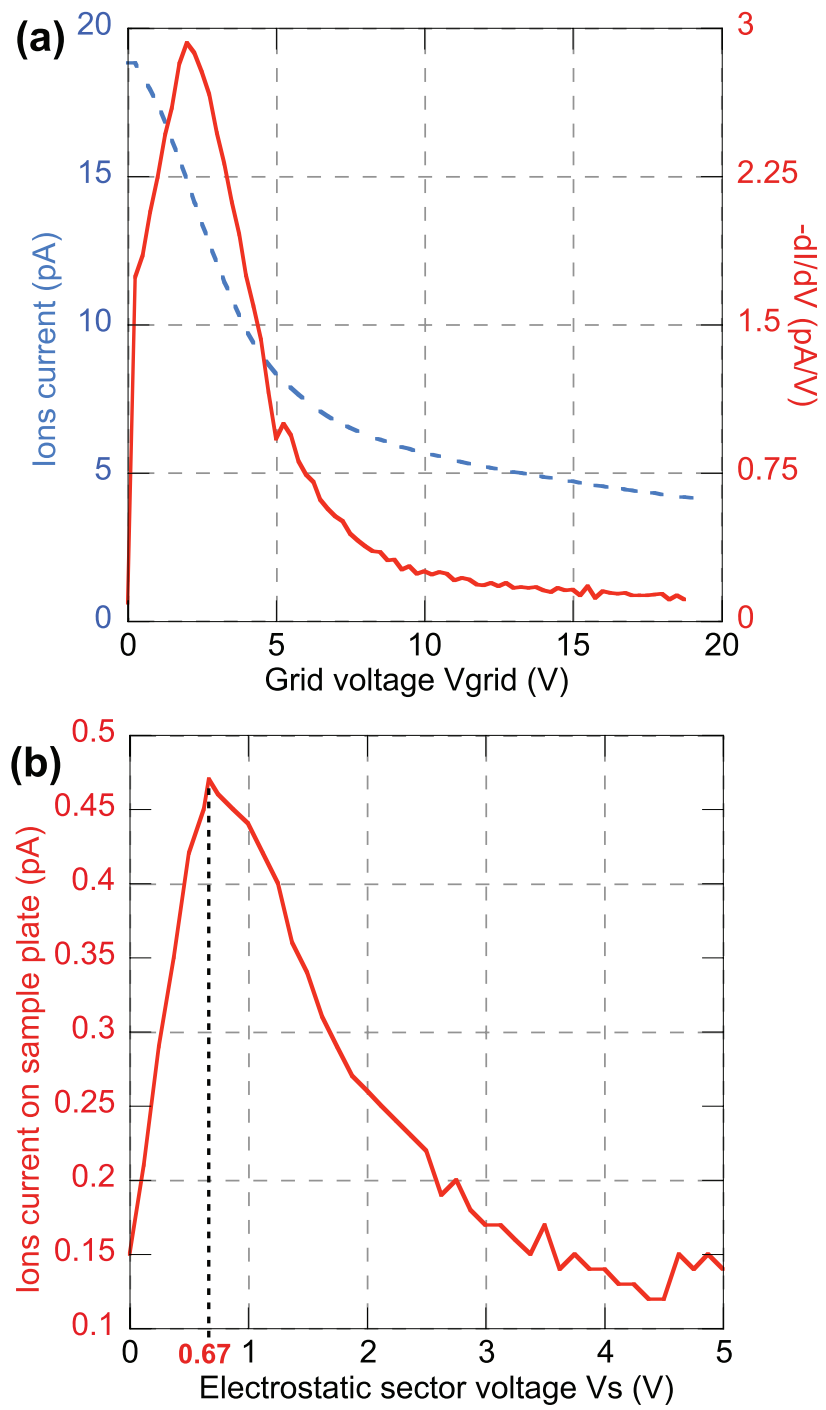

FIG. 10. (a) $\mathrm{I}_{\text {ions }}\left(\mathrm{V}_{\text {grid }}\right)$ (dashed blue curve) and $-\mathrm{dI}_{\text {ions }} / \mathrm{dV}_{\text {grid }}$ (solid red curve) measured for $\mathrm{CF}_{3}{ }^{+}$ions $(\mathrm{m} / \mathrm{z}=69)$. (b) $\mathrm{CF}_{3}{ }^{+}$ion current measured on the plate after the electrostatic sector as a function of the polarization bias of the sector polarized $\mathrm{V}_{\mathrm{s}}$.

high energy tail: even with the grid polarized at $200 \mathrm{~V}$, there is still a current of $0.7 \mathrm{pA}$ that represents $25 \%$ of the total ion current obtained with the grid at $0 \mathrm{~V}$. This means that $25 \%$ of the ions have an energy above $200 \mathrm{eV}$. We checked that the ion current drops to $0 \mathrm{pA}$ when adjusting the $\mathrm{m} / \mathrm{z}$ value at 204 where no ions are present (see Fig. 8). This experimental evidence of the high-energy tail confirms that our simulation of the behavior of the quadrupole is indeed correct. Note that a similar high energy tail was also observed using Q3 in the passing mode and Q1 as the mass filtering quadrupole. ${ }^{20}$

The zoom of $\mathrm{I}_{\text {ions }}\left(\mathrm{V}_{\text {grid }}\right)$ presented in Fig. 9(b) shows that the peak energy of the distribution is $8 \mathrm{~V}$. This value was used to determine the voltage to apply on the electrostatic sector to get the maximum ion current on the substrate.

To determine the efficiency of our electrostatic device to filter in energy of the ion beam, we measured the ion current directly on a metallic plate placed at the output of the electrostatic sector. Since the ion current is very low, the measurements were obtained with the $\mathrm{CF}_{3}{ }^{+}$ions, which are the 
majority ones for the FC43 compound (Fig. 8). Fig 10(a) is the analogous of Fig. 9(b) for these ions. It shows that the maximum energy density for the ion beam at the entrance of the electrostatic sector is at $\mathrm{E}_{\mathrm{f}}=2 \mathrm{eV}$.

Fig. 10(b) shows the ion current measured on the metallic plate after the electrostatic sector as a function of the sector voltage $V_{s}$. The resulting curve has the same shape as $\mathrm{I}_{\text {ions }}\left(\mathrm{V}_{\text {grid }}\right)$, but due to the energy resolution $\Delta \mathrm{E} / \mathrm{E}$ which is constant, it is not possible to extract an $\mathrm{I}_{\text {ions }}\left(\mathrm{E}_{\text {ions }}\right)$ curve from the $\mathrm{I}_{\text {ions }}\left(\mathrm{V}_{\mathrm{s}}\right)$ curve. The maximum is obtained for a value of $\mathrm{V}_{\mathrm{s}}$ $=0.67 \mathrm{~V}$ close to the theoretical value $\mathrm{V}_{\mathrm{s}}=\mathrm{k} \times \mathrm{E}_{\mathrm{f}}=0.333$ $\times 2=0.666 \mathrm{~V}$. At this maximum only $3 \%$ of the ions are transmitted by the electrostatic sector, much below the predicted value of $25 \%$ obtained with the simulation made with ions of $\mathrm{m} / \mathrm{z}=1000$. As explained at the end of Sec. II, the electrostatic sector was optimized for ion of $\mathrm{m} / \mathrm{z}=1000$. Thus, the discrepancy in the sector transmittance between simulation and experiment could be related to the different masses used in the simulation and the experiment.

To check that the ions at the exit of our energy filtering device have a controlled energy, we measured the $\mathrm{CF}_{3}{ }^{+}$ ions current incoming on the metallic plate polarized at $\mathrm{V}_{\text {plate }}$, with an applied voltage $\mathrm{V}_{\mathrm{s}}=0.67 \mathrm{~V}$ corresponding to the maximum current measured previously. The curve $\mathrm{I}\left(\mathrm{V}_{\text {plate }}\right)$ presented in Fig. 11 shows clearly a fast decrease of the ion current when $\mathrm{V}_{\text {plate }}>2.1 \mathrm{~V}$. For $\mathrm{V}_{\text {plate }}>5 \mathrm{~V}$, the ion current cannot be distinguished from the $20 \mathrm{fA}$ noise of the picoammeter. The maximum energy of the ions is below $5 \mathrm{eV}$, meaning that the soft-landing criterion is satisfied. The plot of $-\mathrm{dI} / \mathrm{dV}$ curve allows to better see the energy peak at the exit of the electrostatic sector: the maximum energy is close to $2.4 \mathrm{~V}$ and the FHWM is around $0.7 \mathrm{~V}$ leading to an experimental value of $\Delta \mathrm{E} / \mathrm{E}=0.29$, similar to the simulated values [Fig. 4(d)].

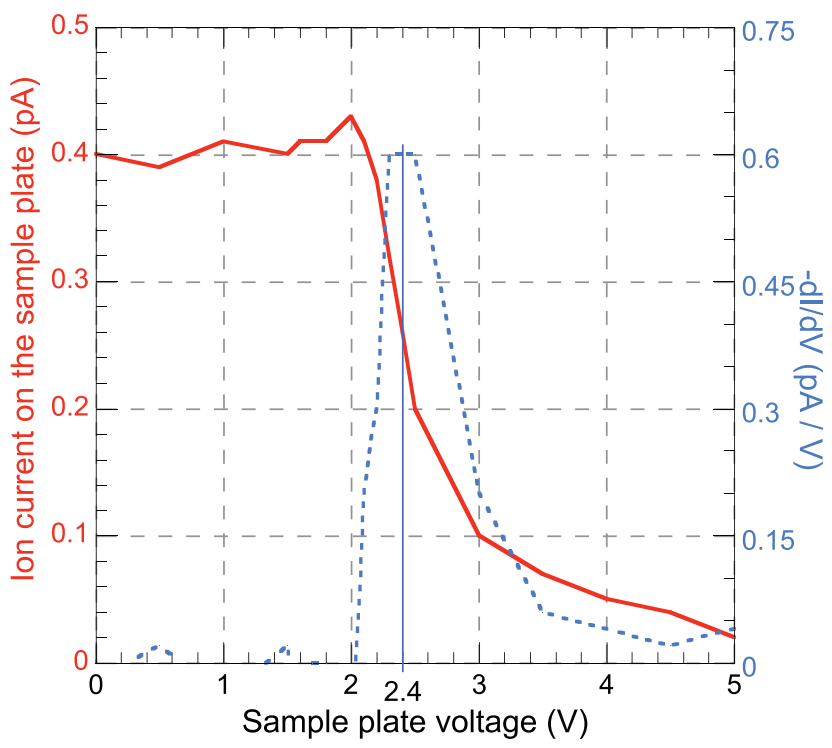

FIG. 11. Doted blue curve : Ion current measured on a metallic plate polarized at $\mathrm{V}_{\text {plate }}$, with the electrostatic sector polarized at $\mathrm{V}_{\mathrm{s}}=0.67 \mathrm{~V}$. Solid red curve: $-\mathrm{dI} / \mathrm{dV}$ curve $(\mathrm{pA} / \mathrm{V})$.

\section{DISCUSSION}

This observation of the high-energy tail is somewhat surprising since the quadrupole technique has been used in many biological or physical types of equipment for more than 50 years. We see two reasons for overlooking it: (1) as already mentioned in the Introduction, it does not impact conventional mass spectrometry; (2) its rather low intensity makes it difficult to detect. We suggest that the observation of fragmentation sometimes mentioned in some of the studies of ionized molecules deposited from a quadrupole could be related to the presence of a non-detected high energy tail in the incident ion beam, for instance, in the works of Cooks and co-workers ${ }^{8}$ and Rauschenbach and co-workers. ${ }^{10}$

Cooks and co-workers ${ }^{8,9}$ studied the soft landing of proteins on surfaces using an homemade rectilinear ion trap mass spectrometer coupled with an ESI source, the landing surface being placed at the exit of the ion trap's back endcap. To measure the kinetic energy distribution of the exiting ions, a retarding potential device was inserted between the ion trap and the sample. The plot of the derivative of the current versus the potential applied to the sample presented a peak shape that was fitted with a Gaussian curve. The interpretation was that the ions had a single peak energy distribution centered on 4 $\mathrm{eV}$ with a standard deviation around $1.5 \mathrm{eV}$. But this result is not compatible with the crash landed molecules observed previously. ${ }^{8}$

Another device designed and used by Rauschenbach and coworkers, ${ }^{10,22}$ allows the deposition of large organic molecules on surfaces under UHV. The molecules are ionized with an ESI source, and then pass through two quadrupoles and two lenses assemblies before reaching the deposition chamber. A TOF-MS can be placed on the ion beam axis for mass spectrometry analysis. The beam energy is measured at the exit of the quadrupole using an einzel lens as a retarding grid energy analyzer. The kinetic energy distribution is measured from the derivative of the measured current with respect to the lens voltage. Like in the study of Cooks et al., ${ }^{9}$ a Gaussian peak is measured for the ion kinetic energy distribution, with a mean energy of $12 \mathrm{eV}$ and a standard deviation of $2.7 \mathrm{eV}$. After deposition, the surface was characterized ex situ using AFM or STM, depending on the substrate type. For bovine serum albumin (BSA, $66300 \mathrm{Da}$ ), fragmentation was not observed on HOPG substrates. But cytochrome C proteins (CytC, $12384 \mathrm{Da})$ deposited on $\mathrm{Cu}(001)$ or $\mathrm{Au}(111)$ substrates, folded but also unfolded proteins were observed. ${ }^{23}$ That the origin of this unfolding could be the consequence of the impact on the substrate surface could not be dismissed entirely. ${ }^{23}$

It is not clear to us why the high energy tail was not observed in these studies. Further work should be performed to reach a better understanding of this high energy tail.

\section{CONCLUSIONS AND PERSPECTIVES}

We have successfully designed and implemented an energy-filtering device coupled to a quadrupole mass spectrometer to allow depositing molecular ions with controlled energy on surfaces. The high-energy tail observed in the kinetic energy distribution of the ion beam at the exit of a 
quadrupole was removed by an energy-filtering device composed of a triplet lenses and a $127^{\circ}$ electrostatic sector. These experiments were performed with an electronic impact ionization source, but an electrospray ionization source can also be used and will not affect the physical behavior of the ions through the quadrupole and the energy-filtering device. The next step will be the characterization of the deposit by scanning probe microscopies.

We are interested in the deposition of very low coverage of large organic molecules for single molecule molecular electronics applications. ${ }^{24}$ For most of these studies, an insulating substrate is preferred. The techniques of choice are then AFM in the non-contact mode ${ }^{25-27}$ coupled to Kelvin Probe Force Microscopy (KPFM) ${ }^{28,29}$ These techniques, when used simultaneously, permit to separate the electrostatic contribution, mainly related to the charge distribution near the surface of the sample from the other forces (mainly van der Waals forces when the tip is not too close to the surface) that contribute to the "topographic" image. KPFM is reasonably well understood when applied to conducting samples, but not on insulating surfaces. We foresee using our modified mass spectrometer to produce insulating samples with calibrated charge deposits to improve our understanding of this technique.

\section{ACKNOWLEDGMENTS}

A.B. gratefully acknowledges financial support from the Nanomol AO3 project of the University Toulouse IIIPaul Sabatier. This work has been supported by the European Commission within the project ARTIST (Contract No. 243421).

${ }^{1}$ R. J. Beuhler, E. Flanigan, L. J. Greene, and L. Friedman, J. Am. Chem. Soc. 96, 3990 (1974).

${ }^{2}$ T. Zambelli, P. Jiang, J. Lagoute, S. Grillo, S. Gauthier, A. Gourdon, and C. Joachim, Phys. Rev. B 66, 075410 (2002).

${ }^{3}$ H. Tanaka and T. Kawai, J. Vac. Sci. Technol. B 15, 602 (1997).

${ }^{4}$ T. Zambelli, Y. Boutayeb, F. Gayral, J. Lagoute, N. K. Girdar, A. Gourdon, S. Gauthier, M.-J. Blanco, J.-C. Chambron, and J.-P. Sauvage, Int. J. Nanosci. 3(3), 331 (2004).

${ }^{5}$ Q. Song, S. A. Smith, L. Gao, W. Xu, M. Voln, Z. Ouyang, and R. G. Cooks, Anal. Chem. 81, 1833 (2009).

${ }^{6}$ O. Hadjar, P. Wang, J. H. Futrell, Y. Dessiaterik, Z. Zhu, J. P. Cowin, M. J. Iedema, and J. Laskin, Anal. Chem. 79, 6566 (2007).

${ }^{7}$ Chr. Hamann, R. Woltmann, I.-P. Hong, N. Hauptmann, S. Karan, and R. Berndt, Rev. Sci. Instrum. 82, 033903 (2011).
${ }^{8}$ Z. Ouyang, Z. Takats, T. A. Blake, B. Gologan, A. J. Guymon, J. M. Wiseman, J. C. Oliver, V. J. Davisson, and R. G. Cooks, Science 301, 1351 (2003).

${ }^{9}$ W.-P. Peng, M. P. Goodwin, Z. Nie, M. Volny, Z. Ouyang, and R. G. Cooks, Anal. Chem. 80, 6640 (2008).

${ }^{10}$ S. Rauschenbach, F. L. Stadler, E. Lunedei, N. Malinowski, S. Koltsov, G. Costantini, and K. Kern, Small 2, 540 (2006).

${ }^{11}$ J. Alvarez, R. G. Cooks, S. E. Barlow, D. J. Gaspar, J. H. Futrell, and J. Laskin, Anal. Chem. 77, 3452 (2005).

${ }^{12}$ J. M. Pomeroy, A. J. Couture, M. V. R. Murty, E. N. Butler, and B. H. Cooper, Rev. Sci. Instrum. 73, 3846 (2002).

${ }^{13}$ P. S. Mayer, F. Turecek, H.-N. Lee, A. A. Scheidemann, T. N. Olney, F. Schumacher, P. Strop, M. Smrcina, M. Patek, and D. Schirlin, Anal. Chem. 77, 4378 (2005).

${ }^{14}$ V. Franchetti, B. H. Solka, W. E. Baitinger, J. W. Amy, and R. G. Cooks, Int. J. Mass Spectrom. Ion Process. 23, 29 (1977).

${ }^{15}$ W. Christen, U. Even, T. Raz, and R. D. Levine, J. Chem. Phys. 108, 10262 (1998); C. Mair, M. Lezius, Z. Herman, and T. D. Märk, ibid. 118, 7090 (2003).

${ }^{16}$ W. Harbich, S. Fedrigo, F. Meyer, D. M. Lindsay, J. Lignières, J. C. Rivoal, and D. Kreisle, J. Chem. Phys. 93, 8535 (1990); S. Fedrigo, W. Harbich, and J. Buttet, Phys. Rev. B 58, 7428 (1998).

${ }^{17}$ D. Martrou, L. Guiraud, R. Laloo, B. Pecassou, P. Abeilhou, O. Guillermet, E. Dujardin, S. Gauthier, J. P. Maris, M. Venegas, A. Hinault, A. Bodin, F. Chaumeton, A. Piednoir, H. Guo, and T. Leoni, in Atomic Scale Interconnection Machines, Advances in Atom and Single Molecule Machines Vol. 1, edited by C. Joachim (Springer-Verlag, Berlin, 2012); H. Guo, D. Martrou, T. Zambelli, E. Dujardin, and S. Gauthier, Rev. Sci. Instrum. 79, 103904 (2008).

${ }^{18} \mathrm{~J}$. T. Watson, Introduction to Mass Spectrometry, 3rd ed. (Lippincott Williams \& Wilkins, Philadelphia, 1997).

${ }^{19}$ B. J. McIntosh and K. L. Hunter, Int. J. Mass Spectrom. Ion Process. 87, 165-179 (1989); K. L. Hunter and B. J. McIntosh, Int. J. Mass Spectrom. Ion Process. 87, 157-164 (1989); W. M. Brubaker, Adv. Mass Spectrom. 4, 293-299 (1968).

${ }^{20}$ See supplementary material at http://dx.doi.org/10.1063/1.4818961 for more results obtained by simulation.

${ }^{21}$ A. Pernot, M. Abignoli, M. Barat, J. Baudon, and A. Septier, Rev. Phys. Appl. 2, 203 (1967).

${ }^{22}$ N. Thontasen, Ph.D. thesis, Ecole Polytechnique Federal de Lausanne, Switzerland, 2006.

${ }^{23}$ Z. T. Deng, N. Thontasen, N. Malinowski, G. Rinke, L. Harnau, S. Rauschenbach, and K. Kern, Nano Lett. 12, 2452 (2012).

${ }^{24}$ C. Joachim, D. Martrou, M. Rezeq, C. Troadec, D. Jie, N. Chandrasekhar, and S. Gauthier, J. Phys.: Condens. Matter 22, 084025 (2010).

${ }^{25}$ R. García and R. Pérez, "Dynamic atomic force microscopy methods," Surf. Sci. Rep. 47, 197 (2002).

${ }^{26}$ F. J. Giessibl, Rev. Mod. Phys. 75(3), 949 (2003).

${ }^{27}$ C. Barth, A. S. Foster, C. R. Henry, and A. L. Shluger, Adv. Mater. 23, 477 (2011).

${ }^{28}$ Kelvin Probe Force Microscopy, edited by S. Sadewasser and Th. Glatzel (Springer, 2012).

${ }^{29}$ A. Hinaut, A. Pujol, F. Chaumeton, D. Martrou, A. Gourdon, and S. Gauthier, Beilstein J. Nanotechnol. 3, 221 (2012). 